\title{
The effect of hot DMSO treatment on the $\gamma$-ray-induced grafting of acrylamide onto PET films
}

\begin{abstract}
Nazia Rahman ${ }^{1}$, Nobuhiro Sato ${ }^{2}$, Masaaki Sugiyama ${ }^{2}$, Yoshiki Hidaka ${ }^{1}$, Hirotaka Okabe ${ }^{1}$ and Kazuhiro Hara ${ }^{1}$
In the present study, the $\gamma$-ray induced grafting of acrylamide (AAm) onto poly(ethylene terephthalate) (PET) films and the resulting changes in properties, including the $\mathrm{Hg}(\mathrm{II})$-capturing functionality, were investigated. No grafting was observed on pristine PET films. Therefore, the films were treated with dimethyl sulfoxide (DMSO) before the $\gamma$-ray grafting with the goal of facilitating grafting; some of the samples were pretreated at high temperature $\left(100-160^{\circ} \mathrm{C}\right)$ and showed a considerable increase in the adsorption of AAm from solution. The highest graft yield obtained in the present study was $15.5 \%$ for the DMSO specimens pretreated at $140^{\circ} \mathrm{C}$ and $\gamma$-ray irradiated with a $100-\mathrm{kGy}$ total dose (1-kGy h${ }^{-1}$ dose rate) in 50 wt\% AAm-monomer solutions in the presence of 1 wt\% $\mathrm{FeCl}_{3}$ (polymerization inhibitor). In addition to the promotion of the graft yield, the formation of micropores in the DMSO-pretreated specimens was found during the optical microscopy investigations. This structural change is hypothesized to assist the adsorption and $\gamma$-ray grafting of AAm to PET. The AAm-grafted PET films prepared using DMSO pretreatment showed high removal efficiency for $\mathrm{Hg}$ (II) ions, whereas the pristine PET film showed no uptake, reflecting these changes.
\end{abstract}

Polymer Journal (2014) 46, 412-421; doi:10.1038/pj.2014.12; published online 19 March 2014

Keywords: acrylamide; Poly(ethylene terephthalate); radiation grafting; swelling agent

\section{INTRODUCTION}

Poly(ethylene terephthalate) (PET) is a thermoplastic polyester with excellent properties, such as mechanical strength, chemical and thermal resistance, and insolubility in the majority of solvents. ${ }^{1}$ Owing to these useful properties and the low production costs, PET is extensively used in packaging, fiber and engineering applications. In addition to these conventional applications, PET has been used as a functional material by attaching amino, carboxylic or other reactive groups to its surface to expand its applications to many fields, such as conductive films, biocompatible materials and recovery agents for heavy metals. ${ }^{1-6}$ To fabricate such highly functional PET, graft copolymerization is a useful technique that causes the covalent bonding of functional monomers onto the polymer surface while maintaining the properties of parent polymer. ${ }^{7-12}$

In the present study, we attempted to bind acrylamide $\left(\mathrm{CH}_{2}=\mathrm{CH}\right.$ $\mathrm{CO}-\mathrm{NH}_{2}, \mathrm{AAm}$ ), a highly water-soluble vinyl monomer well known as the monomer of polyacrylamide (PAAm), to the surface of PET. PAAm has been widely used as a water-soluble thickener in wastewater treatment, gel electrophoresis, papermaking, ore-processing, tertiary oil recovery and the manufacture of permanent press fabrics. In addition to its usage as the starting material for PAAm, AAm has been known to functionalize the surfaces of many polymers by grafting and as an environmental purifying material: ${ }^{13-18} \mathrm{~A}$ reactive fibrous adsorbent prepared using graft copolymerization of AAm onto PET fibers has been studied for the adsorption of $\mathrm{Pb}(\mathrm{II})$ ions from aqueous solution, and the capacity of the adsorbent has been reported to be $39.57 \mathrm{mgg}^{-1}$ of fiber for a graft yield of $15.7 \% .^{13}$ The graft copolymerization of the AAm monomer onto the non-woven, polyethylene-coated polypropylene fabric was carried out using an irradiation method and the uptake of $\mathrm{Cu}(\mathrm{II}), \mathrm{Co}(\mathrm{II})$ and $\mathrm{Ni}(\mathrm{II})$ by the grafted fabrics was evaluated. ${ }^{14}$ Ion-exchange membranes have been prepared via the alkaline hydrolysis of radiation-grafted polyethylenegrafted AAm membranes and an excellent binding capacity of the membranes for mercury ions has been reported. ${ }^{15} \mathrm{AAm}$ has been grafted onto poly(vinyl chloride) using $\gamma$-ray irradiation to prepare ion exchange membranes with a strong tendency to remove ${ }^{60} \mathrm{Co}$ from radioactive liquid waste containing both ${ }^{60} \mathrm{Co}$ and ${ }^{137} \mathrm{Cs} .{ }^{16}$ AAm-grafted sawdust, converted to anion exchanger via treatment with ethylenediamine followed by $\mathrm{HCl}$, has been used effectively for the removal of $\mathrm{Cr}(\mathrm{VI})$ from aqueous solutions. ${ }^{17} \mathrm{AAm}$-based chelating resins prepared using $N, N^{\prime}$-methylene-bis-acrylamide as the crosslinking agent has been studied for the adsorption of $\mathrm{Fe}(\mathrm{III}), \mathrm{Fe}(\mathrm{II}), \mathrm{Ni}(\mathrm{II})$ and $\mathrm{Cu}(\mathrm{II}){ }^{18}$

As mentioned in the preceding paragraphs, the grafting of AAm on PET has been performed through various methods to combine the excellent properties of PET and the characteristic functionality of AAm. Most of the earlier studies used chemical methods of initiation for the grafting of AAm ${ }^{11,13,19,20}$ or other vinyl

${ }^{1}$ Department of Applied Quantum Physics and Nuclear Engineering, Kyushu University, Fukuoka, Japan and 2Division of Quantum Beam Material Science, Research Reactor Institute, Kyoto University Kumatori-cho, Osaka, Japan

Correspondence: N Rahman, Department of Applied Quantum Physics and Nuclear Engineering, Kyushu University, 744 Moto-oka, Fukuoka 8189-0395, Japan. E-mail: nazia@nucl.kyushu-u.ac.jp

Received 9 December 2013; revised 15 January 2014; accepted 19 January 2014; published online 19 March 2014 
monomers ${ }^{4-6,8-10,12,21-25}$ on PET. Although the chemical method produced AAm-grafted PET with high graft yield, it is known that the chemical initiation method is not free from contamination and also that chemical initiation often brings about problems arising from the local heating of the initiator. ${ }^{26}$ Toxic chemical initiators also have the risk of environmental pollution. Therefore, the grafting of AAm through methods other than chemical initiation, such as photografting, 2,27,28 $\mathrm{CO}_{2}$-laser-induced graft copolymerization ${ }^{29}$ or surface-initiated atom transfer radical polymerization ${ }^{3,30}$ has also been investigated. However, the low graft yield obtained using these methods is not suitable for the application of grafted products in the field of heavy metal adsorption or other uses described in the preceding paragraph.

From this point of view, the radiation-induced grafting can be the most suitable method for the grafting of AAm on PET films. The major advantages of radiation grafting are as follows. (a) In a radiation technique, no initiator is required; as free radicals are formed on the polymer/monomer backbone, the purity of the processed products may be maintained. (b) The widespread penetration of ionizing radiation through the polymer matrix ensures rapid and uniform formation of radicals to initiate the grafting process throughout the entire polymer matrix. (c) The reactions can be conducted at room temperatures. (d) The radiation technique generates less environmental pollution than chemical methods. ${ }^{26,31}$ The radiation-induced graft copolymerization of various vinyl monomers, such as acrylic acid, ${ }^{32}$ acrylic acid/acrylonitrile, ${ }^{33}$ acrylic acid/N-vinyl pyrrolidone, ${ }^{34}$ acrylic acid/N-isopropyl $\mathrm{AAm}^{35}$ and $\mathrm{N}$-vinyl pyrrolidone ${ }^{36}$ onto PET fibers and acrylic acid, ${ }^{37}$ styrene, ${ }^{31}$ $n$-butyl acrylate ${ }^{38}$ and $n$-butyl acrylate/styrene ${ }^{39}$ on the PET films demonstrated the high quality of the product generated using radiation-induced grafting for different applications.

However, to the best of the authors' knowledge, no previous studies have reported on the powerful $\gamma$-ray-induced graft copolymerization of AAm onto PET films or fibers. This lack of study is due to serious difficulties in grafting of AAm onto PET films:

(1) the strong propensity of AAm to homopolymerize,

(2) the low diffusion of AAm through PET.

Although homopolymerization (condition 1) is known to be suppressed by some transition metal salts, ${ }^{32}$ condition 2 has been difficult to overcome because the origins lie in the nature of the PET: the high degree of crystallization and ordering of the amorphous regions retard the AAm monomer permeation into the interior of the PET.

Under these conditions, the authors used $\gamma$-ray-induced grafting assisted by dimethyl sulfoxide (DMSO) pretreatment in the present study to attain a higher graft yield of AAm on PET while maintaining the product purity. The effects of grafting on the surface structures and on the mercury $(\mathrm{Hg}(\mathrm{II}))$ adsorption properties of the AAmgrafted PET were comparatively investigated to examine their relationship. $\mathrm{Hg}(\mathrm{II})$ is a well-known toxic material classified as a priority pollutant in spite of being commonly used in many industries; ${ }^{40}$ therefore, the $\mathrm{Hg}$ (II)-capturing property is important from the view point of environmental protection.

\section{MATERIALS AND METHODS}

\section{Materials}

Commercial PET films (Teijin DuPont films, G2) with thicknesses of $50 \mu \mathrm{m}$ were kindly provided by Teijin Co. Ltd (Osaka, Japan). These films were cut into small pieces $(2 \mathrm{~cm} \times 2 \mathrm{~cm})$, washed with acetone and dried in a vacuum oven before use. AAm and $\mathrm{FeCl}_{3}$ were procured from Sigma-Aldrich (St Louis, MO, USA). DMSO and $\mathrm{KOH}$ were supplied by Wako pure chemical industries
Ltd. (Osaka, Japan). $\mathrm{Hg}(\mathrm{II})$ acetate (anhydrous, Chameleon Reagent) and $\mathrm{Hg}$ (II) standard solution (Merck, Darmstadt, Germany) were used as the source of the adsorbate and for the calibration of the metal concentrations, respectively.

\section{Sorption of AAm solution to the DMSO-pretreated PET films}

Dry PET films (weighing $W_{\text {pristine }}$ ) were soaked in DMSO for $0.5 \mathrm{~h}$ at different temperatures (from 60 to $160{ }^{\circ} \mathrm{C}$ ). After withdrawing the PET films from the DMSO, the excess liquid on the PET surface was removed by blotting between filter papers and the weights of the films ( $W_{\text {DMSO }}$ ) were recorded. Then, the films were kept in the AAm aqueous solution (50 wt\%) for $24 \mathrm{~h}$. Moreover, after withdrawing the PET films from the AAm solution, the surface fluid was absorbed using filter paper, and the film weights $\left(W_{\mathrm{AAm} \mathrm{sol}}\right)$ were recorded. Following the previous study, ${ }^{41}$ the ratios of the adsorbed DMSO ( $\delta W_{\text {DMSO }}$ ) and AAm ( $\left.\delta W_{\text {AAm sol }}\right)$ to PET were calculated using the equations below:for the DMSO absorption ratio,

$$
\delta W_{\text {DMSO }}(\%)=\left(W_{\text {DMSO }}-W_{\text {pristine }}\right) / W_{\text {pristine }} \times 100
$$

for the AAm absorption ratio,

$$
\delta W_{\text {AAm sol }}(\%)=\left(W_{\text {AAm sol }}-W_{\text {pristine }}\right) / W_{\text {pristine }} \times 100 .
$$

\section{Grafting of AAm onto DMSO-pretreated PET films}

The DMSO-pretreated PET films were put into several glass bottles containing aqueous AAm solutions with different concentrations (25, 40, 50 and $70 \mathrm{wt} \%)$. After $24 \mathrm{~h}, \mathrm{FeCl}_{3}$ was added to the bottles at a constant concentration $(1 \mathrm{wt} \%)$ to minimize homopolymer formation. Then, the bottles with specimens were $\gamma$-ray-irradiated for different periods in a 1.0$\mathrm{kGy} \mathrm{h}^{-1}$ field (the total doses were $20,50,70$ or $100 \mathrm{kGy}$ ) in the ${ }^{60} \mathrm{Co} \gamma$-ray irradiation facility at the Research Reactor Institute, Kyoto University (the grafting reactions were conducted without deoxygenating the AAm aqueous solutions following previous studies ${ }^{42-44}$ to keep the process convenient and economical). The PET films were removed from the bottles after the irradiation and, then, soaked in $60^{\circ} \mathrm{C}$ distilled water for $24 \mathrm{~h}$ to remove the AAm homopolymers from the films. The rinsed films were dried in a $60^{\circ} \mathrm{C}$ vacuum oven for $24 \mathrm{~h}$ and, finally, the weights of the PET films were measured ( $\left.W_{\text {AAm grafted }}\right)$

The graft yields of the specimens were calculated from the percentage increase in weight $\left(\delta W_{\mathrm{AAm}}\right.$ grafted $)$ as in the previous study ${ }^{41}$ using the equation,

$$
\delta W_{\text {AAm grafted }}(\%)=\left(W_{\text {AAm grafted }}-W_{\text {pristine }}\right) / W_{\text {pristine }} \times 100 .
$$

Moreover, following ${ }^{\text {Ref. }} 24$ the AAm graft densities $(D)$ were derived using the equation,

$$
D\left(\mu \mathrm{g} \mathrm{cm}^{-2}\right)=\left(W_{\text {AAm grafted }}-W_{\text {pristine }}\right) / S
$$

where $S$ is the surface area of the pristine PET sample.

\section{Optical micrograph}

The optical micrographs of the wet and dry PET films after different pretreatments were observed using an optical microscope (Nikon, Tokyo, Japan, Inverted microscope, Eclipse TE 300) with a magnification of $\times 40$.

\section{X-ray diffraction}

$\mathrm{X}$-ray diffraction (XRD) measurements were performed using a SmartLab $\mathrm{X}$-ray diffractometer (Rigaku. ID no: FKOD 12-001). The diffractograms were measured over $2 \theta$ in the range of $5-60^{\circ}$ using $\mathrm{Cu}-\mathrm{K}_{\alpha}$ radiation monochromated with a nickel filter.

\section{Infrared (IR) spectroscopy}

The vibrational spectroscopic analyses of the specimens were performed using a Fourier transform infrared (FTIR) spectrophotometer (Jasco FTIR 620) over a wavenumber range from 400 to $4000 \mathrm{~cm}^{-1}$ to investigate the interactions between the PET matrix and the grafted AAm and, also, to estimate the amount of AAm grafted to PET. 


\section{Scanning electron microscopy}

In addition to the optical microscopic observations over a $100-\mu \mathrm{m}$ range, the minute surface morphologies of the pristine and AAm-grafted PET films were observed using a scanning electron microscope (SEM, Zeiss Ultra55) operated at $10 \mathrm{KeV}$ after carbon coating.

\section{Water uptake measurements}

After weighing $\left(W_{\mathrm{O}}\right)$, each of the pristine and dried AAm-grafted PET films was kept in a beaker filled with distilled water at $25^{\circ} \mathrm{C}$ for $24 \mathrm{~h}$. After this period, the specimens were removed from the containers, and their weights $\left(W_{S}\right)$ were measured immediately after blotting their surfaces. From the measured weights, the water-uptake percentage was calculated using the equation,

Water uptake $(\%)=\left(W_{\mathrm{S}}-W_{\mathrm{O}}\right) / W_{\mathrm{O}} \times 100$.

\section{Hydrolysis of AAm-grafted PET film and $\mathrm{Hg}(\mathrm{II})$ uptake measurements}

The films with a $14 \%$ graft yield were hydrolyzed by $10 \% \mathrm{KOH}$ at $60^{\circ} \mathrm{C}$ for $1 \mathrm{~h}$. Then, each of the 20-mg hydrolyzed AAm-grafted PET films was soaked in $5 \mathrm{ml}$ of an aqueous $100.0 \mathrm{mgl}^{-1}-\mathrm{Hg}$ (II) solution $(\mathrm{pH} \sim 4.5)$ for $40 \mathrm{~min}$ at room temperature $\left(25^{\circ} \mathrm{C}\right)$ to examine the $\mathrm{Hg}$ (II) uptake ability of the hydrolyzed AAm-grafted PET.

Determination of the hydrolysis percentage of AAm. Following the previous study, ${ }^{45}$ the hydrolysis percentage of the amide groups to carboxylate groups was calculated from the IR absorbance using the equation,

Hydrolysis $(\%)=(B-C) /(B-A) \times 100$

where $A, B$ and $C$ are the absorbance ratios of $\left(3200 \mathrm{~cm}^{-1}\right.$ (assigned to $-\mathrm{NH}_{2}$ groups of AAm) $/ 3054 \mathrm{~cm}^{-1}$ (aromatic $-\mathrm{CH}$ stretching vibration of PET)) of the non-grafted, AAm-grafted and hydrolyzed AAm-grafted PET films, respectively.

Determination of the $H g(I I)$ uptake efficiency. Before and after the adsorption, the $\mathrm{Hg}(\mathrm{II})$ concentrations of the aqueous solutions were analyzed using an inductively coupled plasma mass spectrometer (ICP-MS, Agilent7700 Series).
The $\operatorname{Hg}(\mathrm{II})$ uptake efficiencies of the films were calculated using the equation,

$$
\text { Uptake efficiency }(\%)=\left(C_{1}-C_{2}\right) / C_{1} \times 100
$$

where $C_{1}$ and $C_{2}$ are the $\mathrm{Hg}(\mathrm{II})$ concentrations $\left(\mathrm{mgl}^{-1}\right)$ before and after the adsorption, respectively.

\section{RESULTS}

DMSO-assisted grafting of AAm onto PET films by $\gamma$-ray irradiation

The pristine PET films showed no AAm-grafting, despite the fact that those films had been $\gamma$-ray-irradiated in the AAm solution in the usual manner. In this situation, the authors attempted to investigate the AAm grafting onto DMSO-pretreated PET films under various conditions: at several DMSO pretreatment temperatures, in the presence and absence of a polymerization inhibitor, at several AAm-monomer concentrations and at several $\gamma$-ray total doses and dose rates.

Effect of the DMSO pretreatment temperature on the grafting of $A A m$. Before the AAm-solution adsorption, the PET films were pretreated with DMSO at temperatures over the range $60-160{ }^{\circ} \mathrm{C}$. It was found that the specimens pretreated with DMSO over the temperature range $60-140^{\circ} \mathrm{C}$ showed increases in both the DMSO and AAm adsorption (Figure 1), whereas the samples pretreated at $160{ }^{\circ} \mathrm{C}$ showed lower AAm adsorption than that at $140{ }^{\circ} \mathrm{C}$ despite the greater DMSO adsorption. It should also be noted that no significant weight loss was observed for the DMSO-pretreated PET films over the range $60-140{ }^{\circ} \mathrm{C}$.

The $\gamma$-ray grafting of AAm was performed on the DMSOpretreated PET films at 100,140 and $160^{\circ} \mathrm{C}$, which showed significant amounts of DMSO and AAm adsorption. The graft yield was observed to increase as the DMSO-pretreatment temperature increased up to $140{ }^{\circ} \mathrm{C}$ (Figure 1): $5 \%$ at $100{ }^{\circ} \mathrm{C}$ and $14 \%$ at $140{ }^{\circ} \mathrm{C}$ and decreased to $8 \%$ at $160{ }^{\circ} \mathrm{C}$.

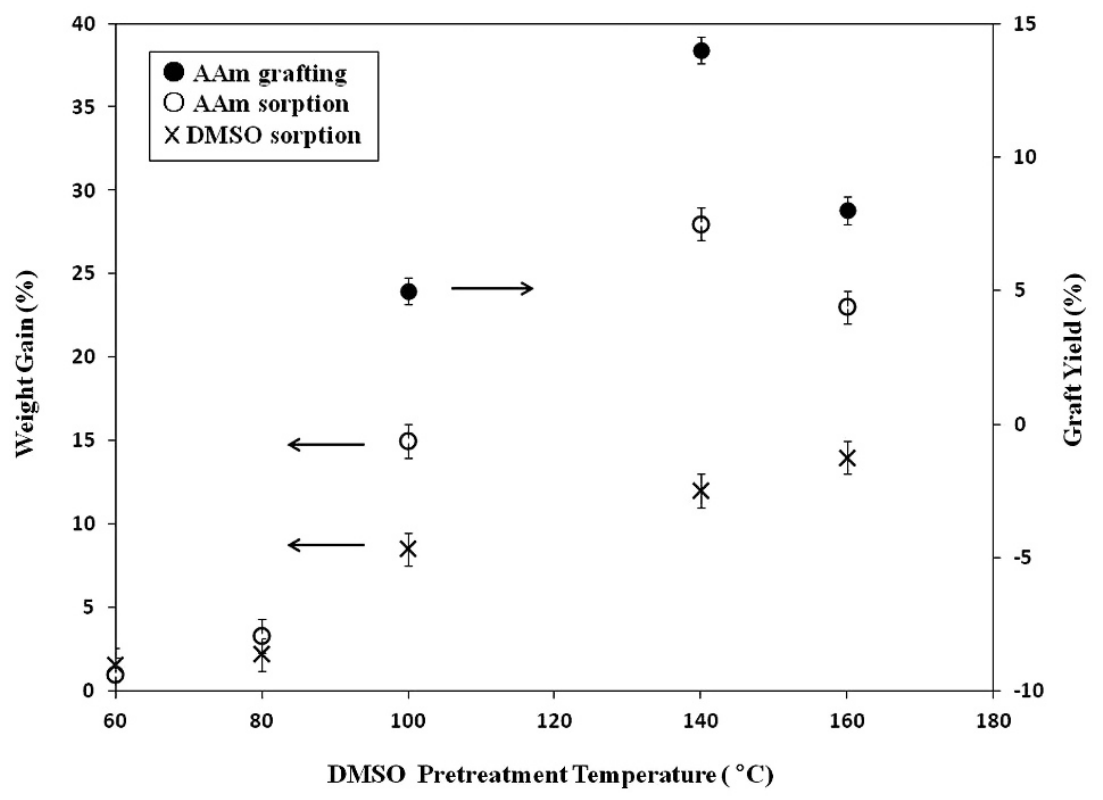

Figure 1 Weight gain ( $\times$ after soaking in DMSO for $0.5 \mathrm{~h}, \bigcirc$ after soaking in 50 wt\% AAm solution for $24 \mathrm{~h}$ ) and graft yield ( $\bullet$ after grafting at $50 \mathrm{wt} \%$ AAm monomer concentration, with a 50-kGy dose at a dose rate of $1 \mathrm{kGyh}^{-1}$, and at $1 \mathrm{wt} \% \mathrm{FeCl}_{3}$ ) as a function of the DMSO pretreatment temperature. 
On the basis of these results for graft yields, the subsequent investigations were performed on the PET films pretreated with DMSO at $140{ }^{\circ} \mathrm{C}$.

Effect of $\mathrm{FeCl}_{3}$ on $\mathrm{AAm}$ grafting. To examine the effect of a polymerization inhibitor $\left(\mathrm{FeCl}_{3}\right)$, the AAm graft yields derived after $\gamma$-ray-grafting process in the presence and absence of $\mathrm{FeCl}_{3}$ were compared while keeping the other conditions the same $\left(140^{\circ} \mathrm{C}\right.$ DMSO-pretreated PET films, grafting at $50 \mathrm{wt} \%$ AAm concentration and $50-\mathrm{kGy}$ radiation dose at a $1-\mathrm{kGy} \mathrm{h}^{-1}$ dose rate). The obtained graft yield was $11 \%$ without $\mathrm{FeCl}_{3}$, which increased to $14 \%$ in the presence of $\mathrm{FeCl}_{3}$. It was also observed that the $\mathrm{AAm}$ solution surrounding the AAm-grafted PET film in the absence of $\mathrm{FeCl}_{3}$ formed a hard gel of homopolymerized PAAms during irradiation, whereas the AAm solution formed a soft gel (for high AAm concentration) or remained liquid (for low AAm concentration) in presence of $\mathrm{FeCl}_{3}$.

Effect of the monomer concentration on the grafting of AAm. To investigate the dependence of the graft yields on the AAm-monomer concentration, the yields obtained after grafting with different monomer concentrations from 25 to $50 \mathrm{wt} \%$ were investigated with the other conditions kept the same $\left(140^{\circ} \mathrm{C}\right.$ DMSO-pretreated PET films, $\gamma$-ray grafting with a $50-\mathrm{kGy}$ radiation dose at a $1-\mathrm{kGy} \mathrm{h}^{-1}$ dose rate in the presence of $1 \mathrm{wt} \% \mathrm{FeCl}_{3}$ ).

The graft yield increased as the monomer concentration increased from 25 to $50 \mathrm{wt} \%$ (Figure 2): $8 \%$ graft yield at $25 \mathrm{wt} \%$ AAm and $14 \%$ for $50 \mathrm{wt} \%$, whereas the graft yield slightly decreased at $70 \mathrm{wt} \%$ of monomer (Figure 2).

Effect of the dose and dose rate on the grafting of AAm. To study the total $\gamma$-ray dose dependence of the graft yield, the graft yields acquired using total doses that varied from 20 to $100 \mathrm{kGy}$ were obtained under the same conditions $\left(140{ }^{\circ} \mathrm{C}\right.$ DMSO-pretreated PET films, $\gamma$-ray grafting at $50 \mathrm{wt} \%$ of $\mathrm{AAm}$ and a $1-\mathrm{kGyh}^{-1}$ dose rate in the presence of $1 \mathrm{wt} \% \mathrm{FeCl}_{3}$; Figure 3).

The graft yield increased as the total dose increased, whereas the rate of increase decreased as the total dose increased (Figure 3).

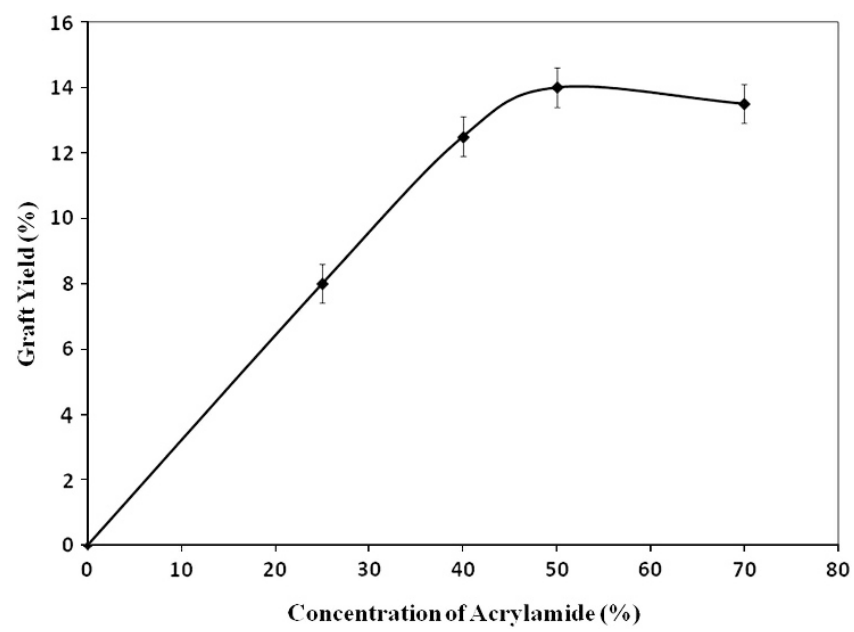

Figure 2 The AAm monomer concentration dependence of the AAm-graft yield onto the $140^{\circ} \mathrm{C}$ DMSO-pretreated PET films while maintaining the other grafting conditions: a 50-kGy total dose, a $1-k_{G y ~ h}{ }^{-1}$ dose rate and the presence of $1 \mathrm{wt} \% \mathrm{FeCl}_{3}$.
In addition to the total $\gamma$-ray dose dependence, the graft yields obtained using two dose rates, 1.02 and $2.40 \mathrm{kGyh}^{-1}$, were investigated while keeping the other conditions same $\left(140^{\circ} \mathrm{C}\right.$ DMSO-pretreated PET films, $\gamma$-ray grafting at $50 \mathrm{wt} \%$ of AAm and a $50-\mathrm{kGy}$ total dose in the presence of $1 \mathrm{wt} \% \mathrm{FeCl}_{3}$ ); however, the graft yield was found to be almost unchanged.

The highest graft yield obtained was $15.5 \%$ for the $140{ }^{\circ} \mathrm{C}$ DMSOpretreated PET films under the following grafting conditions: $50 \mathrm{wt} \%$ AAm monomer, a $100-\mathrm{kGy}$ total dose at a rate of $1 \mathrm{kGyh}^{-1}$, and 1 wt $\% \mathrm{FeCl}_{3}$.

In Table 1 , the $\gamma$-ray graft yield and/or graft density derived in the present study is compared with those obtained from some other methods. ${ }^{3,28-30}$

\section{Optical micrographs of PET films}

The optical micrographs of the surface of the pristine PET films after the different pretreatments are shown in Figure 4. More pores are observed in the micrograph of wet DMSO-pretreated films (Figure $4 \mathrm{~b}$ ) than the pristine PET films (Figure 4a), indicating the formation of micropores on the PET surface by the DMSO pretreatment. The pore structure of the DMSO-pretreated film changed after soaking in an AAm solution, which became more significant in the

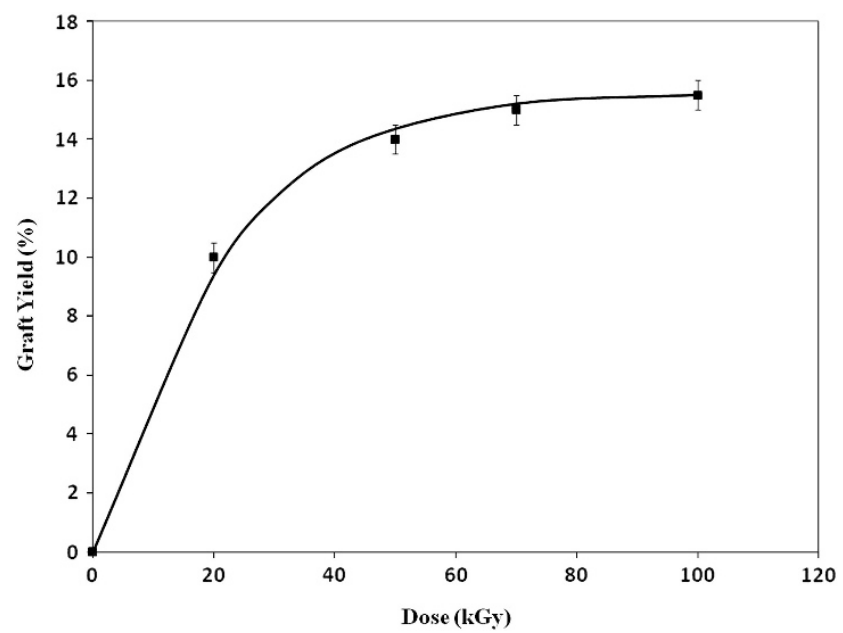

Figure 3 The total $\gamma$-ray dose dependence of the AAm-graft yield on the $140^{\circ} \mathrm{C}$ DMSO-pretreated PET films with all other grafting conditions held constant: 50 wt $\%$ AAm, a $1-\mathrm{kGy} \mathrm{h}^{-1}$ dose rate and the presence of $1 \mathrm{wt} \%$ $\mathrm{FeCl}_{3}$.

Table 1 A comparison of graft yield and/or graft density derived in the present study ( $\gamma$-ray) with the results obtained using other methods

\begin{tabular}{|c|c|c|}
\hline Grafting method & Graft yield (\%) & Graft density $\left(\mu \mathrm{g} \mathrm{cm}^{-2}\right)$ \\
\hline UV radiation 24 & $0.3^{a}$ & - \\
\hline UV radiation 22 & - & $10^{\mathrm{a}}$ \\
\hline $\mathrm{CO}_{2}$ laser $^{23}$ & - & $359^{a}$ \\
\hline SI-ATRP24 & $1.37^{\mathrm{a}}$ & - \\
\hline SI-ATRP 3 & $2.52^{\mathrm{a}}$ & - \\
\hline$\gamma$-ray irradiation (present study) & $15.5( \pm 0.5)$ & $1125( \pm 25)$ \\
\hline
\end{tabular}

Abbreviations: SI-ATRP, surface-initiated atom transfer radical polymerization; UV, ultraviolet. aThe values are described as they appear in the references. 

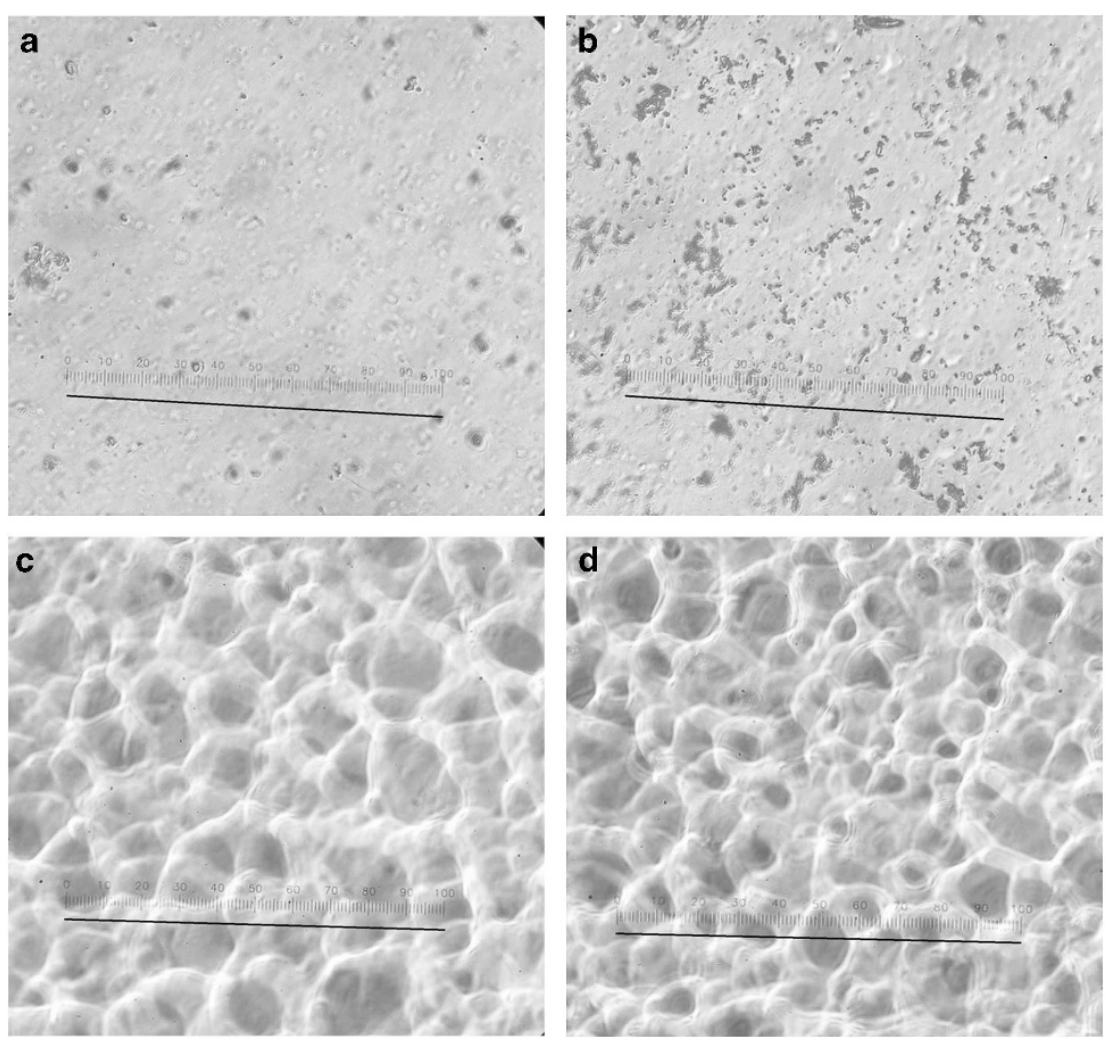

Figure 4 Optical micrographs of (a) the pristine PET film, (b) the DMSO-pretreated (at $140{ }^{\circ} \mathrm{C}$ ) wet film, (c) the wet AAm-solution-soaked DMSO-pretreated film (DMSO pretreated at $140^{\circ} \mathrm{C}$ and soaked in 50 wt $\%$ AAm solution) and (d) AAm-grafted PET film (DMSO pretreated at $140{ }^{\circ} \mathrm{C}$ and $\gamma$-ray irradiated with a $50-\mathrm{kGy}$ dose at a $1-\mathrm{kGy} \mathrm{h}^{-1}$ dose rate in the presence of $1 \mathrm{wt} \% \mathrm{FeCl}_{3}$ after soaking in $50 \mathrm{wt} \% \mathrm{AAm}$ solution) (The black line inside each figure represents $100 \mathrm{~mm}$ ). A full color version of this figure is available at Polymer Journal online.

wet AAm-solution-soaked PET film (Figure 4c). The surface structure of the AAm-grafted film resembled that of the wet AAm-solutionsoaked DMSO-pretreated film (Figure 4d).

The optical micrographs of the PET films were also studied to investigate the effect of the DMSO-pretreatment temperatures on the surface structure. Figure 5 shows the optical micrographs of the PET films after DMSO pretreatment at $100^{\circ} \mathrm{C}$ (Figure 5a), $140{ }^{\circ} \mathrm{C}$ (Figure 5c) and $160^{\circ} \mathrm{C}$ (Figure 5e) as well as the samples soaked in AAm solution after the DMSO treatment (Figures $5 \mathrm{~b}, \mathrm{~d}$ and $\mathrm{f}$ ), respectively.

As shown in Figure 5, the number of pores and their diameters increased with increasing pretreatment temperature, which promoted monomer diffusion into the polymer matrix.

\section{XRD analysis of PET films}

XRD analyses were performed on the pristine PET film, the DMSOpretreated wet PET film (pretreated at $140{ }^{\circ} \mathrm{C}$ ), the AAm-soaked $(50$ wt $\%$ AAm solution) wet film (after DMSO pretreatment at $140{ }^{\circ} \mathrm{C}$ ) and the AAm-grafted PET film (DMSO-pretreated at $140{ }^{\circ} \mathrm{C}$ and $\gamma$-ray-irradiated with a $50-\mathrm{kGy}$ dose at a $1-\mathrm{kGyh}^{-1}$ dose rate in the presence of $1 \mathrm{wt} \% \mathrm{FeCl}_{3}$ after soaking in $50 \mathrm{wt} \%$ AAm solution). The investigation showed that the amount of the crystalline phase in the PET film increased significantly after the treatment with DMSO (Figure 6b). The AAm-soaked wet film showed little increase in the degree of crystallinity compared with the DMSO-treated film (Figure 6c). However, the AAm-grafted film showed a significant decrease in the degree of crystallinity compared with the AAm-soaked wet film (Figure 6d).

\section{FTIR spectroscopic analysis of PET films}

To investigate the effects of the AAm grafting, the IR spectra of pristine PET and the AAm-grafted PET films were investigated and compared over the wavenumber ranges from 3800 to $2400 \mathrm{~cm}^{-1}$ (Figure 7a) and $1700-1450 \mathrm{~cm}^{-1}$ (Figure 7b). The grafted films used for the IR analyses were DMSO-pretreated at $140{ }^{\circ} \mathrm{C}$ and immersed in 25,40 and $50 \mathrm{wt} \%$ AAm solutions. They were $\gamma$-ray-irradiated with a $50-\mathrm{kGy}$ total dose at a $1-\mathrm{kGy} \mathrm{h}^{-1}$ dose rate in the presence of $1 \mathrm{wt} \%$ $\mathrm{FeCl}_{3}$. New peaks appeared, which indicated grafting onto PET and were assigned to the AAm groups, whereas the other characteristic peaks of PET remained almost unchanged. Specifically, in the spectra of the AAm-grafted PET films, the newly observed peaks at 3350 and $3200 \mathrm{~cm}^{-1}$ were assigned to the asymmetric and symmetric stretching vibrations of the $-\mathrm{NH}_{2}$ groups of AAm, respectively. The intensity of the peaks related to the $-\mathrm{NH}_{2}$ groups increased with the graft-yield percentage as shown in Figure 7a; in addition, a new shoulder peak also appeared at $1672 \mathrm{~cm}^{-1}$, which was assigned to the vibration of carbonyl amide (Figure 7b). The characteristic peaks of PET and AAm observed in the present study agreed well with the values reported in the literature. ${ }^{3,4}$

As shown in Figure 7c, the ratio of the IR absorption intensity of the $3200-\mathrm{cm}^{-1}$ peak (assigned to the $\mathrm{NH}_{2}$ symmetric stretching of $\mathrm{AAm}$ ) to the $3054-\mathrm{cm}^{-1}$ peak (assigned to the aromatic $\mathrm{CH}$ 

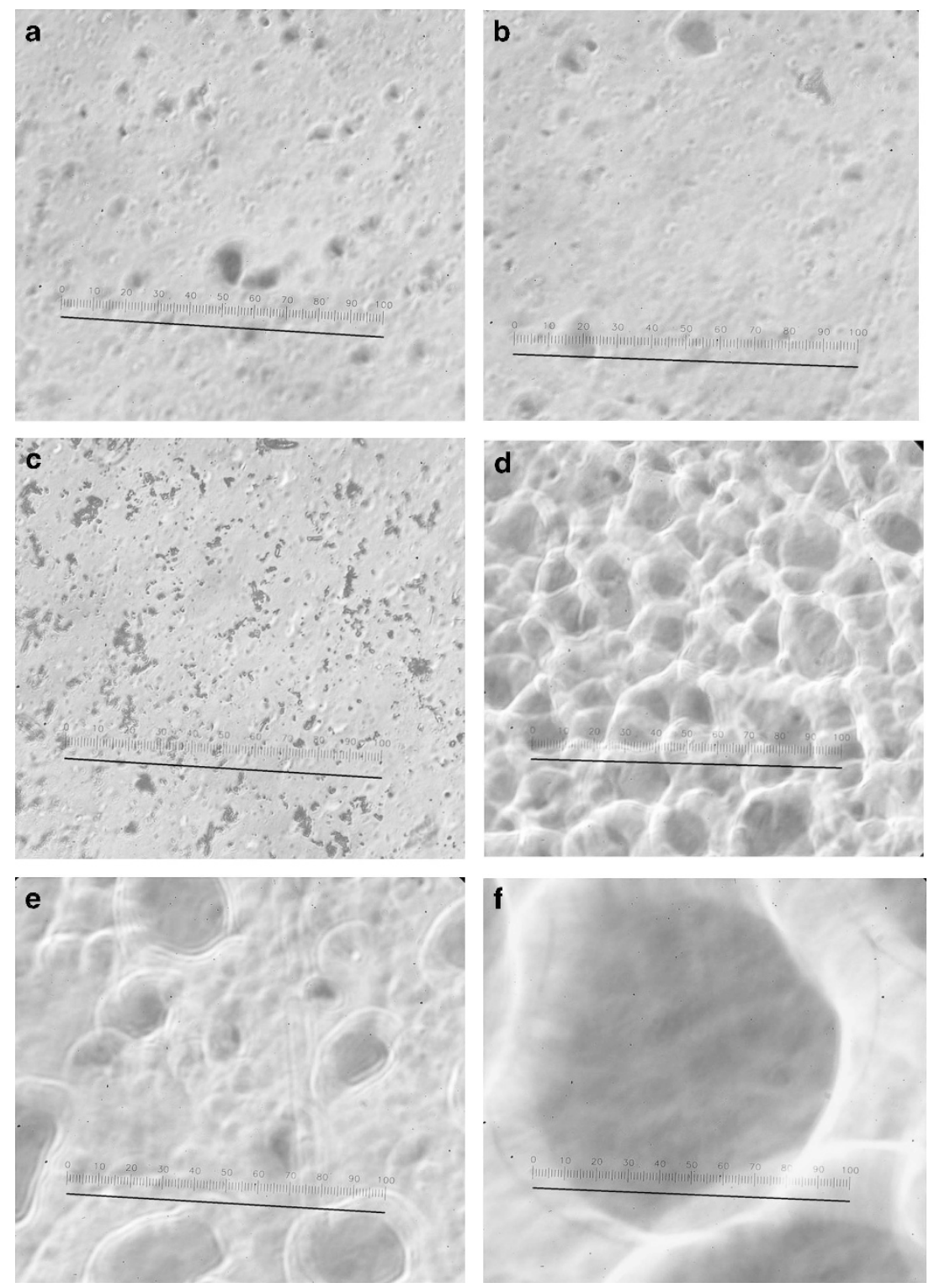

Figure 5 Optical micrographs of the wet PET films with (a) DMSO pretreatment at $100^{\circ} \mathrm{C}$, (b) AAm sorption (50 wt $\%$ AAm solution) after (a), (c) DMSO pretreatment at $140{ }^{\circ} \mathrm{C}$, (d) AAm sorption (50 wt\% AAm solution) after (c), (e) DMSO pretreatment $160^{\circ} \mathrm{C}$, and (f) AAm sorption (50 wt\% AAm solution) after (e) (The black line inside each figure represents $100 \mathrm{~mm}$ ). A full color version of this figure is available at Polymer Journal online.

stretching of PET) showed a linear dependence on the AAm-graft yield (calculated from the gravimetric data).

\section{Scanning electron microscopic analysis of PET films}

The surface textures of the pristine PET and AAm-grafted-PET films were observed using SEM to probe the morphological changes after AAm grafting at a smaller scale than the optical microscopy. The grafted films used for the SEM analyses were DMSO-pretreated at $140{ }^{\circ} \mathrm{C}$ and $\gamma$-ray-irradiated with a $50-\mathrm{kGy}$ dose at a $1-\mathrm{kGy} \mathrm{h}^{-1}$ dose rate in the presence of $1 \mathrm{wt} \% \mathrm{FeCl}_{3}$ after soaking in a $50 \mathrm{wt} \% \mathrm{AAm}$ solution. An SEM micrograph of the pristine PET film is shown in Figure 8a and an image of the AAm-grafted PET film and its contrastenhanced image are shown in Figure $8 \mathrm{~b}$ and $\mathrm{c}$ and, respectively. From the micrographs, it is clear that the AAm grafting caused significant changes in the surface morphologies of the PET films.

\section{Water-uptake measurements}

AAm-grafted PET films with different yields (from 0 to 14\%) were prepared for experiments that measured the water uptake (after DMSO pretreatment at 100 or $140{ }^{\circ} \mathrm{C}$, immersion in a 25 or $50 \mathrm{wt} \%$ AAm solution, and $\gamma$-ray irradiation with a $50-\mathrm{kGy}$ total dose at a $1-\mathrm{kGy} \mathrm{h}^{-1}$ dose rate in the presence or absence of $1 \mathrm{wt} \% \mathrm{FeCl}_{3}$ ). The water uptake percentages of the AAm-grafted PET films in distilled water are shown in Figure 9. The water uptake percentage simply increased with the graft yield, despite the various preparation conditions.

\section{$\mathrm{Hg}(\mathrm{II})$ uptake}

The pristine PET film showed no $\mathrm{Hg}$ (II) adsorption. To increase the accessibility of the metal ions to the amide groups, the AAm-grafted films (DMSO-pretreated at $140{ }^{\circ} \mathrm{C}, \gamma$-ray-irradiated with a $50-\mathrm{kGy}$ dose at a $1-\mathrm{kGyh}^{-1}$ dose rate in the presence of $1 \mathrm{wt} \% \mathrm{FeCl}_{3}$ after 

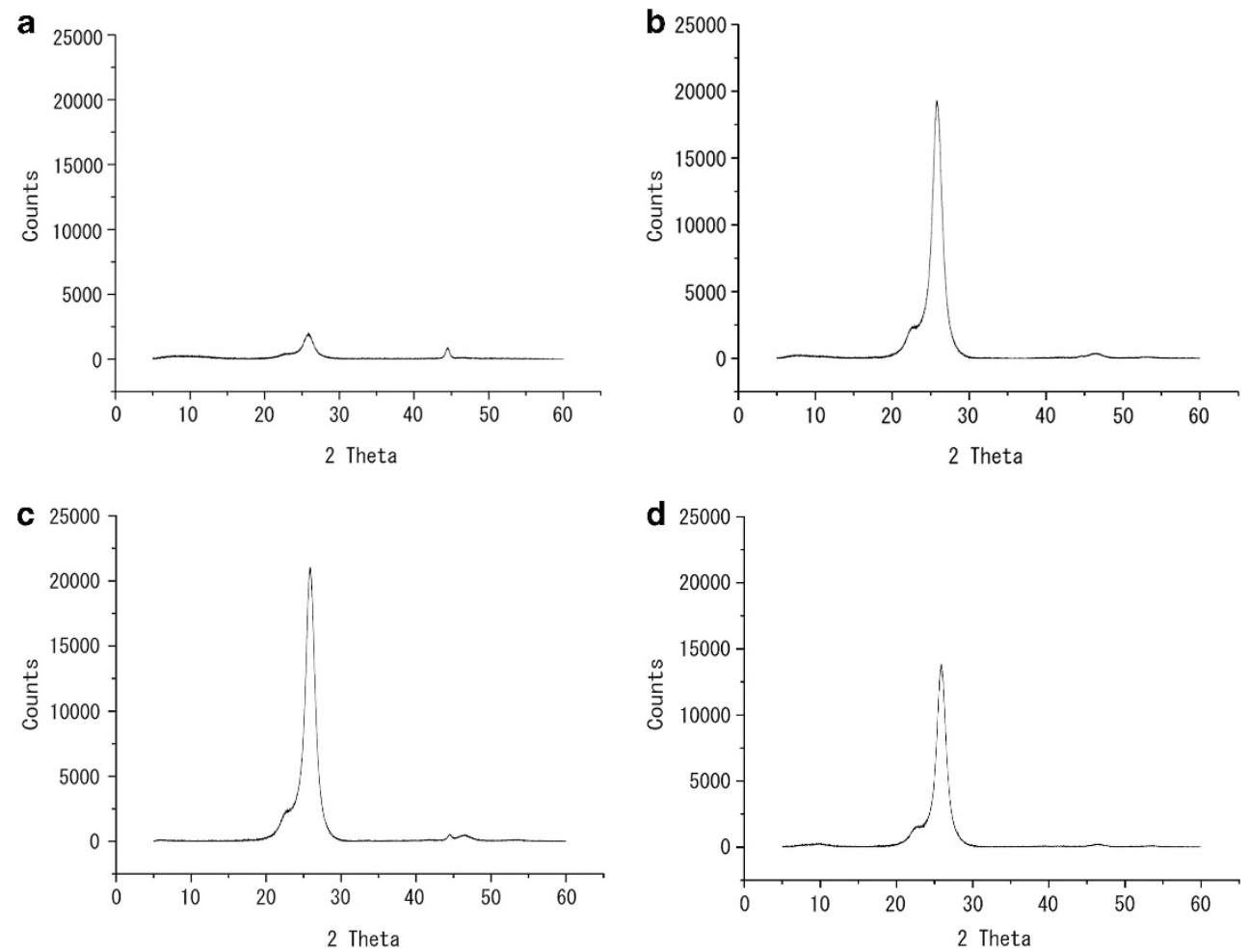

Figure 6 X-ray diffractograms of (a) pristine PET film, (b) wet PET films with DMSO pretreatment at $1400^{\circ} \mathrm{C}$, (c) AAm-soaked (50 wt \% AAm solution) wet film after DMSO pretreatment at $140^{\circ} \mathrm{C}$, (d) AAm-grafted PET film (DMSO-pretreated at $140^{\circ} \mathrm{C}$ and $\gamma$-ray irradiated with a 50-kGy dose at a 1 -kGy h-1 dose rate in the presence of $1 \mathrm{wt} \% \mathrm{FeCl}_{3}$ after soaking in $50 \mathrm{wt} \%$ AAm solution).

soaking in $50 \mathrm{wt} \%$ AAm solution) with a $14 \%$ graft yield were partially hydrolyzed by $\mathrm{KOH}$ (the hydrolysis percentage was $\sim 30 \%),{ }^{15}$ and the hydrolyzed films were used to examine the $\mathrm{Hg}$ (II) adsorption capacity. The hydrolyzed, AAm-grafted PET films showed high removal efficiency for $\mathrm{Hg}$ (II) ions (Table 2).

\section{DISCUSSION}

In the present study, the authors investigated the $\gamma$-ray-induced grafting of AAm onto PET films. During the AAm grafting, the SEM photographs demonstrated changes in the morphology of the PET surface, indicating the emergence of graft chains on its surface. This observation is the most fundamental condition necessary for water and $\mathrm{Hg}(\mathrm{II})$ uptake because the water uptake is related to the hydrophilicity of the AAm group, and the $\mathrm{Hg}$ (II) uptake is expected to come from the ability of the AAm amide groups to form covalent bonds with $\mathrm{Hg}(\mathrm{II})$ ions. In addition to the SEM images, the FTIR spectra of the AAm-grafted PET films also showed peaks that were not observed in the pristine PET film, which were assigned to the symmetric and asymmetric stretching of the $\mathrm{AAm} \mathrm{NH}_{2}$ group. The authors confirmed a linear relationship between the graft yield (obtained using the gravimetric method) and the normalized absorbance at $3200 \mathrm{~cm}^{-1}$ (assigned to the $\mathrm{NH}_{2}$ symmetric stretching of AAm) divided by the absorbance at $3054 \mathrm{~cm}^{-1}$ (assigned to the aromatic $\mathrm{CH}$ stretching of PET). These features demonstrate the evolution of the AAm graft in the PET matrix. It is very difficult to distinguish between PAAms covalently bonded to PET or firmly entangled in PET; however, by taking into account the water solubility of the monomeric AAm or homopolymerized PAAms, it is expected that almost all of the non-bonded PAAms were partitioned into the water after a 24-h washing of the AAm-grafted PET films at high temperature, as described in Materials and methods section. Actually, the water- and $\mathrm{Hg}(\mathrm{II})$-uptake capacities of the grafted films were considerably larger than those of the pristine PET film, reflecting the emergence of grafted AAm chains in the PET matrix.

During the investigations, the authors found that the graft yield and, correspondingly, the adsorption capabilities were increased considerably by the DMSO treatments of the PET surfaces at high temperatures $\left(100-140{ }^{\circ} \mathrm{C}\right)$ before the grafting procedure. The highest graft yield obtained in the present work was $15.5 \%$ under conditions of $140{ }^{\circ} \mathrm{C}$ for the DMSO-pretreatment temperature, $50 \mathrm{wt} \%$ of the AAm monomer and a $100-\mathrm{kGy}$ total dose (dose rate: $1 \mathrm{kGy} \mathrm{h}^{-1}$ ) in 1 wt $\%$ of $\mathrm{FeCl}_{3}$ solution, which is much higher than that achieved using other non-chemical grafting techniques, such as UV irradiation, a $\mathrm{CO}_{2}$ laser or the surface-initiated atom transfer radical polymerization method (Table 1). In addition to the increase in the graft yield, the optical micrographs observed after the high-temperature DMSO pretreatments demonstrated the formation of micropores on the PET surfaces. These pores are hypothesized to facilitate the permeation of the AAm monomers into the PET matrix and to assist the subsequent AAm grafting as well as increase the graft-possible surface area. As no significant weight losses were measured in the PET specimens after the DMSO pretreatments, the pore formation is not believed to occur via the dissolution or extraction of PET but due to the dislocation of PET polymer chains caused by the interaction between DMSO and PET. The details on this phenomenon are described in the following paragraphs.

As is often experienced, AAm grafting on the pristine PET film was not successful, which might be due to the high degree of crystallization and ordering of the amorphous regions of PET that retards monomer diffusion. In the present work, the authors attempted to 

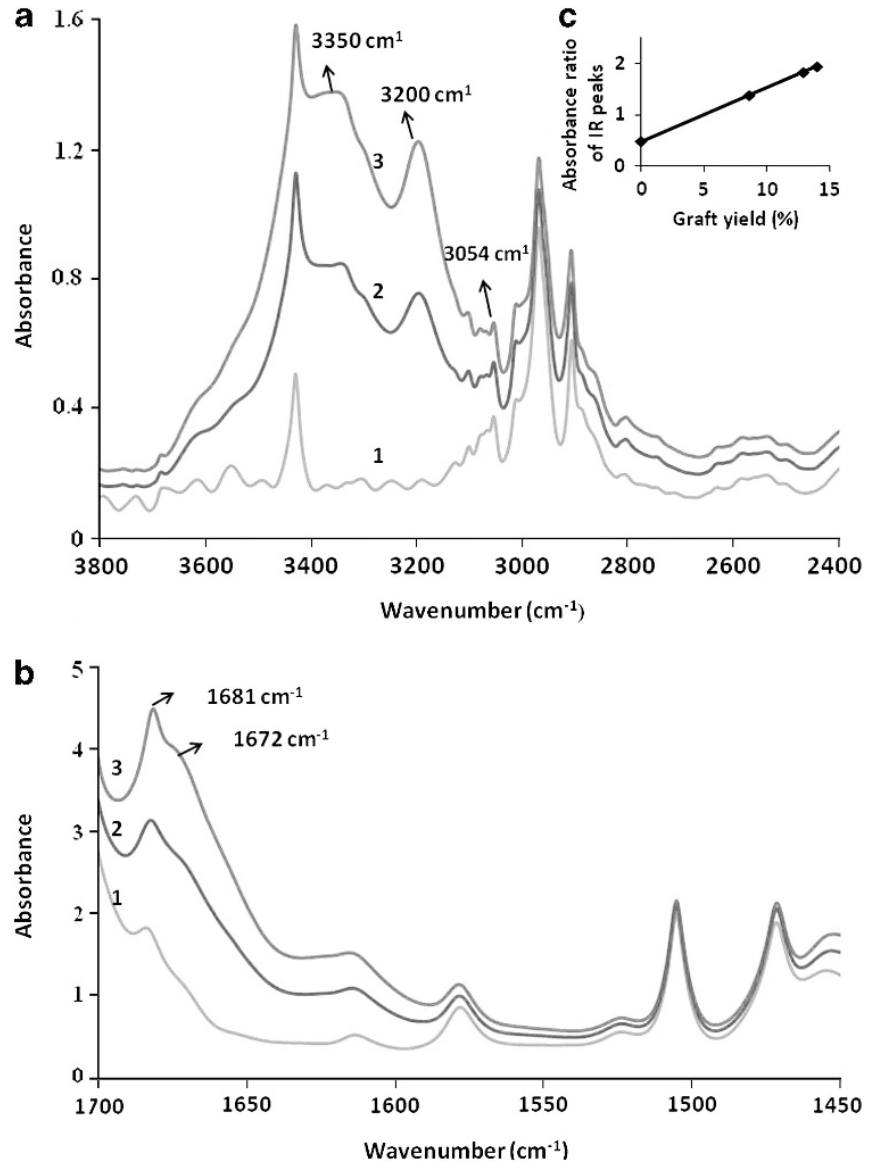

Figure 7 FTIR spectra in the (a) higher and (b) lower wavenumber regions for (1) pristine PET, (2) the AAm-grafted PET with an $8.6 \%$ graft yield, and (3) with a $12.9 \%$ graft yield. (c) The graft yield dependence of the absorbance ratio of the IR peak at $3200 \mathrm{~cm}^{-1}$ to that at $3054 \mathrm{~cm}^{-1}$. A full color version of this figure is available at Polymer Journal online.

treat the PET films with DMSO before the AAm- $\gamma$-induced grafting, which considerably increased the graft yield. The reasons for adopting DMSO is hypothesized as follows: solvents with similar solubility parameters to PET will swell the PET's surface, which will provide enough energy to disrupt the intermolecular cohesive forces between the polymer chains and will permit chain mobility. ${ }^{46,47}$ During this process, surface pore formation can occur, depending on the interaction degree between the solvent and the polymer. ${ }^{48}$ PET is an $(\mathrm{AB})$ alternating copolymer, where $\mathrm{A}$ is the semirigid aromatic segment $-\mathrm{CO}-\mathrm{C}_{6} \mathrm{H}_{4}$ - with 9.5 as the solubility parameter $(\delta)$, and $\mathrm{B}$ is a flexible aliphatic ester - $\mathrm{CO}-\mathrm{O}-\mathrm{CH}_{2}-\mathrm{CH}_{2}$ - with $\delta=12.0$. As the $\delta$ of the aliphatic ester portion is very close to that of DMSO $(\delta=12.9)$, the situation is favorable for AAm diffusion into PET and the subsequent grafting onto it. ${ }^{20}$

The pretreatment of the PET film with DMSO at high temperatures may increase the interaction between PET and DMSO and, consequently, this interaction can promote pore formation on the PET surface, which facilitates the diffusion of AAm into the polymer matrix. Although negligible for the pristine PET film, the AAm solution adsorption increased with increasing DMSO pretreatment temperature over the range from 60 to $140{ }^{\circ} \mathrm{C}$ and reached a maximum value, $28 \%$, for a film treated at a temperature of $140{ }^{\circ} \mathrm{C}$ (Figure 1). Although this trend can be explained by the preceding discussion, there were also different features observed for the specimen pretreated at $160{ }^{\circ} \mathrm{C}$ (Figure 1): the AAm solution adsorption decreased, which is most likely due to the extraction of the lowmolecular-weight PET and partial dissolution of PET in DMSO at $160^{\circ} \mathrm{C} .{ }^{7,49}$ The DMSO pretreatment temperature dependence of the AAm-grafting degree agrees with the AAm adsorption, which indicates a close relationship between the AAm absorption amount and the grafting yield.

The effect of the DMSO pretreatment on the structure of the PET film that aids the diffusion of AAm is further revealed via XRD analysis of the films. The XRD results show an increase in the crystalline phase after DMSO treatment. It is hypothesized that DMSO penetration into the PET matrix enhanced the segmental mobility of the macromolecules in the amorphous phase, which made the diffusion of the AAm monomer into the PET matrix easier. As a result of the enhancement of the segmental mobility of the macromolecules in the amorphous phase induced by DMSO, the volume of the crystallites that existed in PET before the DMSO treatment increased. ${ }^{44}$ Moreover, the reduction in the degree of crystallinity after AAm grafting might be due to the disordering of the chain structures of the PET matrix caused by the amorphous AAm grafts. Dilution of the crystalline structure of PET after graft co-polymerization is also reported in previous studies. ${ }^{31,37}$

As for the homopolymerization inhibitor, the AAm grafting was investigated in the presence and absence of a homopolymerization inhibitor, $\mathrm{FeCl}_{3}$ : the $\mathrm{FeCl}_{3}$ addition enabled a significant reduction in the AAm homopolymerization. The formation of a hard gel of homopolymerized PAAm in the AAm solution surrounding the AAm-grafted PET film in absence of $\mathrm{FeCl}_{3}$ made the separation of the AAm-grafted PET surface from the ungrafted AAm monomers laborious. Conversely, in the presence of $\mathrm{FeCl}_{3}$, the surrounding $\mathrm{AAm}$ solution formed a soft gel (for high AAm concentration) or remained liquid (for low AAm concentration) and, consequently, the separation between the AAm-grafted PET surface and the ungrafted AAm monomers became easier. The facile separation of the grafted product from the monomers is an important consideration for practical application of the graft copolymerization method. Owing to the reduction of the homopolymerization, larger amounts of AAm monomers are estimated to be available for the AAm grafting on PET and the graft yield is thought to increase. In the present study, the graft yield increased over the AAm-monomer concentration ranging from 25 to $50 \mathrm{wt} \%$ without homopolymerization, whereas the yield decreased above $50 \mathrm{wt} \%$ where noticeable homopolymerization was observed.

The authors also investigated the total- $\gamma$-ray-dose dependence of the graft yield over the range from 20 to $100 \mathrm{kGy}$. The graft yield increased linearly in the lower dose region and showed saturation at higher doses. This saturation feature could be due to an increase in the obstruction of the AAm-monomer permeation during the $\gamma$-ray irradiation due to the growing and extending mass of $\gamma$-grafted AAm on the PET surface. In addition to this saturation feature of the dose dependence, the graft yield also showed a similar behavior in the dependence on the $\gamma$-ray dose rate from 1.02 to $2.40 \mathrm{kGyh}^{-1}$. One might think that the phenomenon also originates from the abovementioned homopolymerization: the graft yield could become lower in the above mentioned homopolymerizing system because the doserate increase would promote the AAm homopolymerization, which would increase the solution viscosity and restrict monomer diffusion. However, such an adverse effect was not expected in the present case because the AAm solution was incorporated into the DMSOpretreated PET films before irradiation. Additionally, the $\mathrm{FeCl}_{3}$ should reduce the homopolymerization during the $\gamma$-ray irradiation. 

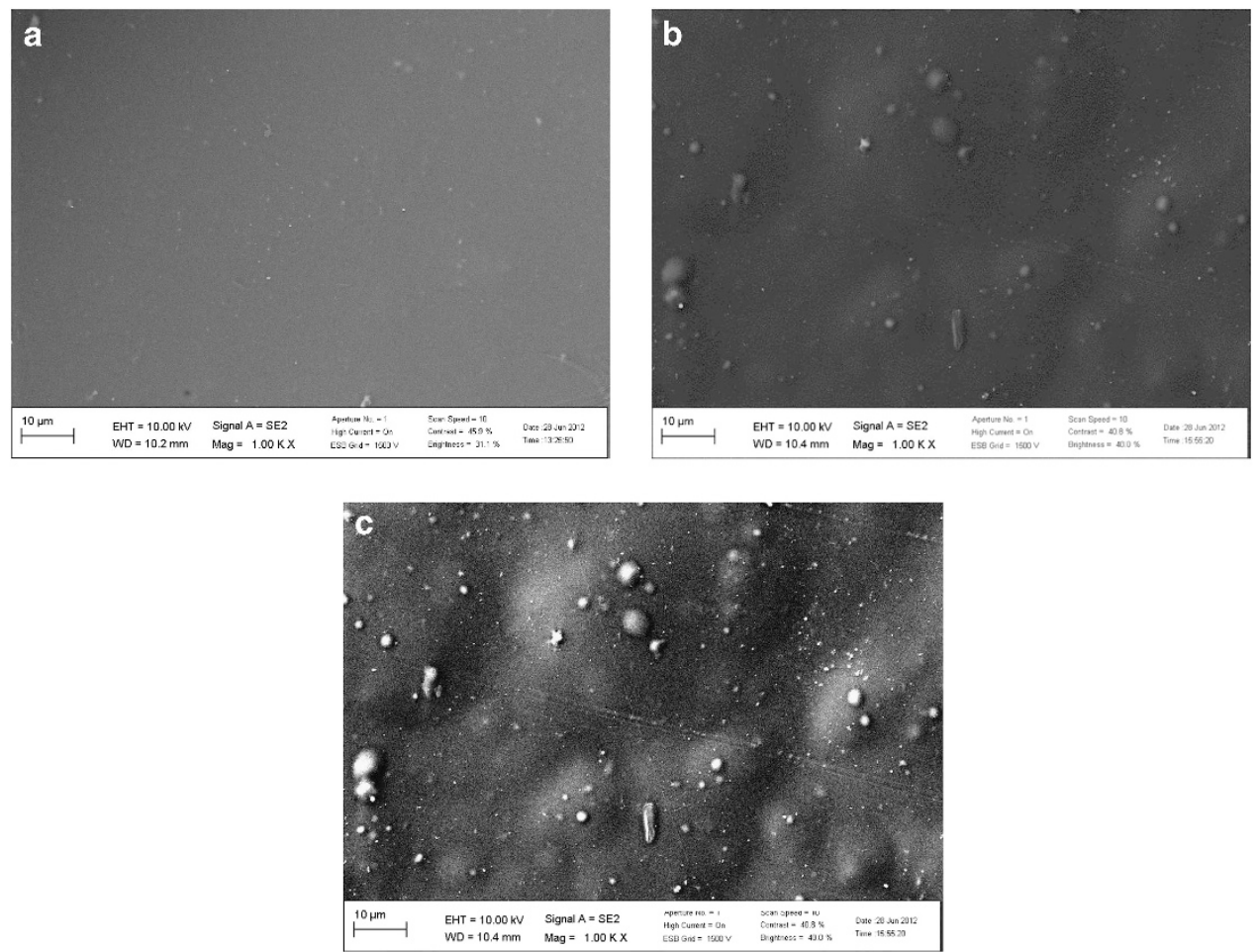

Figure 8 (a) SEM micrographs of pristine PET film surfaces, (b) SEM micrographs of the AAm-grafted PET film, (c) the contrast-enhanced image of (b).

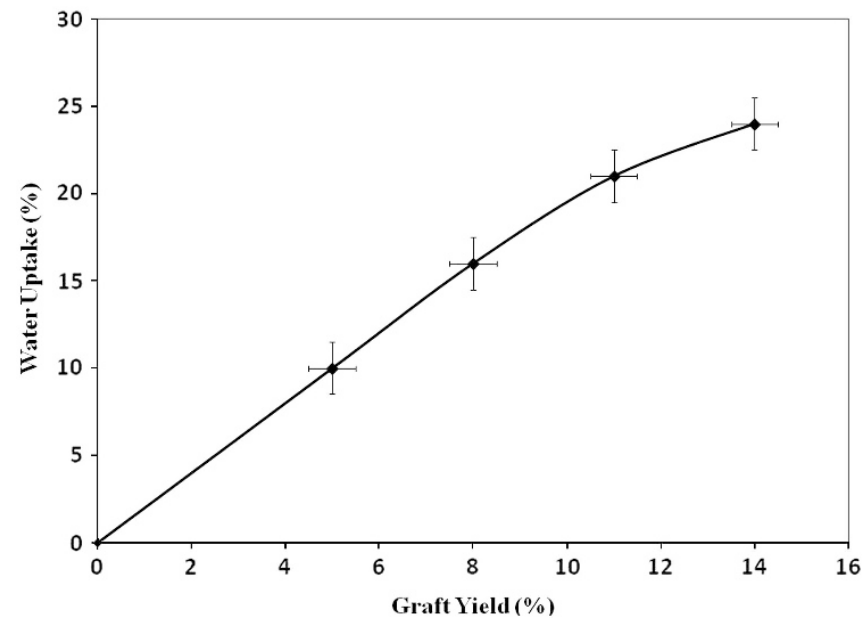

Figure 9 The graft yield dependence of the water uptake in the AAm-grafted PET films.

Table 2 The removal of $\mathrm{Hg}(\mathrm{II})$ ions by the pristine PET and the hydrolyzed, AAm-grafted PET filmsAbbreviations: AAm, acrylamide; $\mathrm{PET}$, poly(ethylene terephthalate)

\begin{tabular}{llc}
$\begin{array}{l}\text { Initial } \mathrm{Hg}(I I) \\
\text { concentration }\left(m g /^{-1}\right)\end{array}$ & Sample adsorbent & $($ II) removal \\
\hline $100.0( \pm 0.5)$ & $\begin{array}{l}\text { Pristine PET film } \\
\text { Hydrolyzed AAm-grafted PET film }\end{array}$ & 0 \\
& $96( \pm 1)$ \\
\hline
\end{tabular}

\section{CONFLICT OF INTEREST}

The authors declare no conflict of interest.

\section{ACKNOWLEDGEMENTS}

This work was supported by JSPS KAKENHI Grant Number 24360398.

1 Arslan, M. Preparation and use of amine-functionalized glycidyl methacrylate-g poly(ethylene terephthalate) fibers for removal of chromium(VI) from aqueous solution. Fiber Polym. 11, 325-330 (2010).

2 Wirsén, A., Sun, H. \& Albertsson, A. C. Solvent-free vapor-phase photografting of acrylamide onto poly(ethylene terephthalate). Biomacromolecule 6, 2697-2702 (2005)

3 Zhang, H., Du, Z., Jiang, Y. \& Yu, Q. Preparation and characterization of grafting polyacrylamide from PET films by SI-ATRP via water-borne system. J. Appl. Polym. Sci. 126, 1941-1955 (2012).

4 Coşkun, R., Soykan, C. \& Saçak, M. Removal of some heavy metal ions from aqueous solution by adsorption using poly(ethylene terephthalate)-g-itaconic acid/acrylamide fiber. React. Funct. Polym. 66, 599-608 (2006).

5 Yiğitoğlu, M. \& Arslan, M. Adsorption of hexavalent chromium from aqueous solutions using 4-vinyl pyridine grafted poly(ethylene terephthalate) fibers. Polym. Bull. 55, 259-268 (2005).

6 Yiğitoğlu, M. \& Arslan, M. Selective removal of $\mathrm{Cr}(\mathrm{VI})$ ions from aqueous solutions including $\mathrm{Cr}(\mathrm{VI}), \mathrm{Cu}(\mathrm{II})$ and $\mathrm{Cd}(\mathrm{II})$ ions by 4-vinly pyridine/2-hydroxyethylmethacrylate monomer mixture grafted poly(ethylene terephthalate) fiber. J. Hazard. Mater. 166 435-444 (2009).

7 Hsieh, Y. L., Shinawatra, M. \& Castillo, M. D. Postirradiation polymerization of viny monomers on poly(ethylene terephthalate). J. Appl. Polym. Sci. 31, 509-519 (1986)

8 Abdel-Bary, E. M., Sarhan, A. A. \& Abdel-Razik, H. H. Effect of graft copolymerization of 2-hydroxyethyl methacrylate on the properties of polyester fibers and fabric. J. Appl. Polym. Sci. 35, 439-448 (1986).

9 Saçak, M. \& Oflaz, F. Benzoyl-peroxide-initiated graft copolymerization of poly(ethylene terephthalate) fibers with acrylic acid. J. Appl. Polym. Sci. 50, 1909-1916 (1993).

10 Saçak, M., Sertkaya, F. \& Talu, M. Grafting of poly(ethylene terephthalate) fibers with methacrylic acid using benzoyl peroxide. J. Appl. Polym. Sci. 44, 1737-1742 (1992).

11 Sanli, O., Aytemiz, S. \& Ünal, H. İ. Graft Copolymerization of acrylamide on swollen poly(ethylene Teraphtalate) fibers using cerium ammonium nitrate initiator. J. Macromol. Sci. Pure Appl. Chem. 34, 1003-1015 (1997). 
12 Rao, K. N., Rao, M. H., Lokhande, H. T., Mody, N. R. \& Jog, A. G. Grafting onto polyester fibers. II. Kinetics of grafting of acrylic acid, acrylonitrile, and vinyl acetate onto polyester fibers. J. Appl. Polym. Sci. 23, 2133-2138 (1979).

13 Coşkun, R. \& Soykan, C. Lead(II) adsorption from aqueous solution by poly(ethylene terephthalate)- $\gamma$-acrylamide fibers. J. Polym. Res. 13, 1-8 (2006).

14 Ibrahim, S. M., El-Salmawi, K. M. \& El-Naggar, A. A. Use of radiation grafting of polyethylene-coated polypropylene nonwoven fabric by acrylamide for the removal of heavy metal ions from wastewaters. J. Appl. Polym. Sci. 102, 3240-3245 (2006).

15 Gupta, B. \& Anjum, N. Preparation of ion-exchange membranes by the hydrolysis of radiation-grafted polyethylene-g-polyacrylamide films: properties and metal-ion separation. J. Appl. Polym. Sci. 90, 3747-3752 (2003).

16 Maziad, N. A., Sayed, M. S. \& Hegazy, E. A. Use of radiation grafted PVC-acrylamide membranes in radioactive waste treatment. Polym. Int. 51, 155-155 (2002).

17 Raji, C. \& Anirudhan, T. S. Batch $\mathrm{Cr}(\mathrm{VI})$ removal by polyacrylamide grafted sawdust: kinetics and thermodynamics. Wat. Res. 32, 3772-3780 (1998).

18 Latha, A. G., George, B. K., Kannam, K. G. \& Ninan, K. N. Synthesis of a polyacrylamide chelating resin and applications in metal ion extractions. J. Appl. Polym. Sci. 43, 1159-1163 (1991).

19 Sacak, M. \& Pulat, E. Benzoyl-peroxide-initiated graft copolymerization of poly (ethylene terephthalate) fibers with acrylamide. J. Appl. Polym. Sci. 38, 539-546 (1989).

20 Şanli, O. \& Pulat, E. Solvent-assisted graft copolymerization of acrylamide on poly (ethylene terephthalate) films using benzoyl peroxide initiator. J. Appl. Polym. Sci. 47, 1-6 (1993).

21 Karakısla, M. The Adsorption of $\mathrm{Cu}(\mathrm{II})$ Ion from aqueous solution upon acrylic acid grafted poly(ethylene terephthalate) fibers. J. Appl. Poly. Sci. 87, 1216-1220 (2003).

22 Băg, H., Türker, A. R., Coșkun, R., Saçak, M. \& Yiğitoğlu, M. Determination of zinc, cadium, cobalt and nickel by flame atomic absorption spectrometry after preconcentration by poly_ethylene terephthalate/ fibers grafted with methacrylic acid. Spectrochimica Acta Part B 55, 1101-1108 (2000).

23 Bozkaya, O., Yiğitoğlu, M. \& Arslan, M. Investigation on selective adsorption of $\mathrm{Hg}($ II) ions using 4-vinyl pyridine grafted poly(ethylene terephthalate) fiber. J. Appl. Poly. Sci. 124, 1256-1264 (2012).

24 Çoşkun, R., Soykan, C. \& Saçak, M. Separation and Purification Technology 49, 107 114 (2006).

25 Arslan, M. Preparation and use of amine-functionalized glycidyl methacrylate-gpoly(ethylene terephthalate) fibers for removal of chromium(VI) from aqueous solution. Fibers and Polymers 11, 325-330 (2010).

26 Bhattacharya, A. \& Misra, B. N. Grafting: a versatile means to modify polymers techniques, factors and applications. Prog. Polym. Sci. 29, 767-814 (2004).

27 Yao, Z. P. \& Ranby, B. Surface modification by continuous graft copolymerization. III. Photoinitiated graft copolymerization onto poly (ethylene terephthalate) fiber surface. J. Appl. Polym. Sci. 41, 1459-1467 (1990).

28 Uchida, E., Uyama, Y. \& Ikada, Y. A novel method for graft polymerization onto poly (ethylene terephthalate) film surface by UV irradiation without degassing. J. Appl. Polym. Sci. 41, 677-687 (1990).

29 Dadsetan, M., Mirzadeh, H. \& Sanjani, N. S. Surface modification of polyethylene terephthalate film by $\mathrm{CO}_{2}$ laser-induced graft copolymerization of acrylamide. J. Appl. Polym. Sci. 76, 401-407 (2000).

30 Zhou, C., Zhang, H. W., Jiang, Y., Wang, W. J. \& Yu, Q. Grafting of polyacrylamide from poly(ethyleneterephthalate) films. J. Appl. Polym. Sci. 121, 1254-1261 (2011).

31 Nasef, M. M. Gamma radiation-induced graft copolymerization of styrene onto poly(ethylene terephthalate) films. J. Appl. Polym. Sci. 77, 1003-1012 (2000).
32 Gupta, B., Grover, N. \& Singh, H. Radiation grafting of acrylic acid onto poly(ethylene terephthalate) fabric. J. Appl. Polym. Sci. 112, 1199-1208 (2009).

33 El-Arnaouty, M. B., Abdel Ghaffar, A. M. \& El Shafey, H. M. Radiation-induced graft copolymerization of acrylic acid/acrylonitrile onto LDPE and PET films and its biodegradability. J. Appl. Polym. Sci. 107, 744-754 (2008).

34 Gupta, B., Grover, N., Mohanty, S., Jain, K. G. \& Singh, H. Radiation grafting of acrylic acid/N-vinyl pyrrolidone binary mixture onto poly(ethylene terephtha- late) fabric and growth of human mesenchymal stem cell. J. Appl. Polym. Sci. 115, 116-126 (2010).

35 Gupta, B., Mishra, S. \& Saxena, S. Preparation of thermosensitive membranes by radiation grafting of acrylic acid/ $\mathrm{N}$-isopropyl acrylamide binary mixture on $\mathrm{PET}$ fabric. Radiat. Phys. Chem. 77, 553-560 (2008)

36 El-Gendy, E. H., Ali, N. M. \& El-Shanshoury, I. A. Processes involved during radiation grafting of $\mathrm{N}$-vinyl pyrrolidone onto poly(ethylene terephthalate) fabric. J. Appl. Polym. Sci. 101, 3009-3022 (2006).

37 Kattan, M. \& El-Nesr, E. $\gamma$-Radiation-induced graft copolymerization of acrylic acid onto poly(ethyleneterephthalate) films: a study by thermal analysis. J. Appl. Polym. Sci. $102,198-203$ (2006).

38 Ping, X., Wang, M. \& Ge, X. Radiation induced graft copolymerization of n-butyl acrylate onto poly(ethylene terephthalate) (PET) films and thermal properties of the obtained graft copolymer. Radiat. Phys. Chem. 80, 632-637 (2011).

39 Ping, X., Wang, M. \& Ge, X. The study on grafting comonomer of $n$-butyl acrylate and styrene onto poly(ethylene terephthalate) film by gamma-ray induced graft copolymerization. Radiat. Phys. Chem. 79, 941-946 (2010).

40 Molinari, R., Poerio, T., Cassano, R., Picci, N. \& Argurio, P. Copper(II) removal from wastewaters by a new synthesized selective extractant and SLM viability. Ind. Eng. Chem. Res. 43, 623-628 (2004).

41 You-Lo, H., Pugh, C. \& Ellison, M. S. The effects of selected organic solvents on the polymerization of acrylic acid to poly(ethylene terephthalate) by glow discharge. J. Appl. Polym. Sci. 29, 3547-3560 (1984).

42 Goel, N. K., Bhardwaj1, Y. K., Manoharan, R., Kuma1, V., Dubey, K. A., Chaudhari, C. V. \& Sabharwal, S. Physicochemical and electrochemical characterization of battery separator prepared by radiation induced grafting ofacrylic acid onto microporous polypropylene membranes. Exp. Polym. Lett. 3, 268-278 (2009).

43 Tuhin, M. O., Rahman, N., Haque, M. E., Khan, R. A., Dafader, N. C., Islam, R., Nurnabi, M. \& Tonny, W. Modification of mechanical and thermal property of chitosanstarch blend films. Radiat. Phys. Chem. 81, 1659-1668 (2012).

44 Martinovich, V. I. \& Polikarpov, A. P. Effect of heat and solvent treatment on radiation grafting of acrylic acid to poly(ethylene terephthalate). High Energy Chem. 40, 149-153 (2006).

45 Faterpeker, S. A. \& Potnis, S. P. Radiation grafting of poly(Ethylene terephthalate) (PET) fibre, II hydrolysis of grafted poly(viny acetate) to poly(viny1 alcohol). Angew. Makromol. Chem. 93, 111-129 (Nr. 1425) (1981).

46 Ribnick, A. S., Weigmann, H. D. \& Rebenfeld, L. Interactions of nonaqueous solvents with textile fibers: part I: effect of solvents on the mechanical properties of a polyester yarn. Text. Res. J. 42, 720-726 (1972).

47 Knox, B. H., Weigmann, H. D., Scott, M. G. \& Rebenfeld, L. The Effects of an aqueous medium on the structure and physical properties of a polyester yarn. Text. Res. J. 51, 549-558 (1981).

48 Jameel, H., Noether, H. D. \& Rebeneld, L. The effects of orientation and crystallinity on the solvent-induced crystallization of poly (ethylene terephthalate). II. Physical structure and morphology. J. Appl. Polym. Sci. 27, 773-793 (1982).

49 Jameel, H., Waldman, J. \& Rebeneld, L. The effects of orientation and crystallinity on the solvent-induced crystallization of poly (ethylene terephthalate). I. Sorption- and diffusion-related phenomena. J. Appl. Polym. Sci. 26, 1795-1811 (1981). 